\title{
A Cross-Sectional Analytical Study of Knowledge and Practice of Exercise among Hypertensive Patients attending NCD Clinic in Western Gujarat
}

\author{
Amrita Sarkar ${ }^{1, *}$, Mittal Rathod $^{2,}{ }^{,}$, Nirmika Patel $^{3}$, Meet Chauhan $^{4}$, Naresh Makwana $^{5}$, Dipesh Parmar
}

Amrita Sarkar ${ }^{1, *}$, Mittal Rathod ${ }^{2, *}$, Nirmika Patel ${ }^{3}$, Meet Chauhan ${ }^{4}$, Naresh Makwana ${ }^{5}$, Dipesh Parmar 6

\section{'Senior Resident Doctor, Department of Community Medicine, North Eastern Indira Gandhi Regional Institute Health and Medical Sciences (NEIGRIHMS), Shillong: 793018, Meghalaya, INDIA. \\ ${ }_{2}^{2}$ Post MD Tutor, Department of Community Medicine, Shri MPShah Government Medical College, Jamnagar, Gujarat, INDIA. ${ }^{3}$ Tutor, Department of Community Medicine, GMERS, Ahmedabad, Gujarat, INDIA. \\ ${ }^{4}$ Assistant Professor, Department of Com- munity Medicine, Pacific Institute of Medical Sciences, Udaipur, Rajasthan, INDIA. \\ SProfessor, Department of Community Medicine, Shri MP Shah Government Medical College, Jamnagar, Gujarat, INDIA. \\ ${ }^{6}$ Professor and Head, Department of Com munity Medicine, Shri MP Shah \\ Government Medical College, Jamnagar, Gujarat, INDIA. \\ Correspondence \\ Dr. Mittal Rathod \\ Post MD Tutor, Department of \\ Community Medicine, Shri MP Shah \\ Government Medical College, Jamnagar, \\ Gujarat, INDIA. \\ Phone no: 9033334649 \\ Email:dr.mittal74@gmail.com}

\section{Dr. Amrita Sarkar}

Senior Resident Doctor, Department of Community Medicine, North Eastern

Indira Gandhi Regional Institute of Health and Medical Sciences (NEIGRIHMS),

Mawdiangdiang, Shillong 793018, INDIA.

Phone no: 7002129302

Email: 2amritasarkar@gmail.com

History

- Submission Date: 16-05-2018

- Revised Date: 18-09-2018

- Accepted Date: 16-11-2018

DOI : 10.5530/ijmedph.2018.4.29

Article Available online

http://www.ijmedph.org/v8/i4

\section{Copyright}

(C) 2018 Phcog.Net. This is an openaccess article distributed under the terms of the Creative Commons Attribution 4.0 International license.

\begin{abstract}
Introduction: Hypertension is a serious public health problem, globally and can be controlled by proper adherence to medications and lifestyle modifications. Though the efficacy of exercise in lowering blood pressure is a proven fact, little is known about the knowledge and practice of exercise in hypertensive. This study aimed at assessing the knowledge and practice of exercise in the hypertensive patients and finding the correlates of the knowledge. Materials and Methods: This hospital-based, cross-sectional study was done among 400 hypertensive patients attending NCD clinic at tertiary care hospital and 5 CHCs of Jamnagar district of Gujarat from July 2013 to June $2014.50 \%$ of the sample was collected from the tertiary care centre where as remaining $50 \%$ were selected from 3 selected $\mathrm{CHCs}$ by simple random sampling technique. Pre-tested semi structured proforma was used to collect information from participants by one to one interview. Results: The majority (67.5\%) were not aware regarding the benefits of exercise in hypertension and only $8.3 \%$ exercised. Patients who were exercising had 9.39 times more odds of higher knowledge of its benefit as compared to those who were not $(p<0.05)$. The most common form of exercise was walking $(87.9 \%)$. Majority $(90.9 \%)$ practised for less than $30 \mathrm{~min} /$ day while only $27.3 \%$ exercised for at least 5 days/week. Younger the age group, more aware about benefit of exercise. Same was observed for male gender, urban area residence. Conclusion: Exercise is a cornerstone of such self-care behaviours, however knowledge and practice of exercise were found to be poor in the present study. Proper communication and motivation by health professional especially focussing on high risk groups observed in this study is of utmost importance.
\end{abstract}

Key words: Hypertension, Non-communicable diseases, NCD.

\section{INTRODUCTION}

Hypertension (HTN) is a chronic, non-communicable disease (NCD) that is endemic worldwide and is a leading cause of morbidity and mortality. Presently, around one billion people are suffering from HTN in the world ${ }^{1}$ which is expected to increase to 1.56 billion people by $2025 .{ }^{2}$ The prevalence of HTN is on the rise in most of the developing countries including India ${ }^{3}$ where the situation is quite alarming as around $33 \%$ urban and 25\% rural Indians are hypertensive. ${ }^{4} \mathrm{HTN}$ is not only the most common cardiovascular disease (CVD) but also the most important risk factor for other CVDs. ${ }^{1,5} \mathrm{HTN}$ is directly responsible for $57 \%$ of all stroke deaths and $24 \%$ of all CHD deaths in India. ${ }^{6}$ Being a controllable disease, this fact is important as a population-wide decrease of $2 \mathrm{mmHg}$ in $\mathrm{BP}$ can prevent 151,000 stroke and 153,000 CHD deaths in India. ${ }^{7}$ But also results in higher health care expenditure. ${ }^{8}$ Various guidelines and epidemiological studies have recommended that lifestyle modifications such as increase in physical activity and exercise should be both used for primary of HTN. ${ }^{1,9}$ However, in India though with changing lifestyle and demographic transition, HTN is on the rise, the status of selfcare measures like adherence to medication, recommended diet, exercise is often poor amongst the patients. This fact prompted to conduct the present study with an aim to assess the knowledge and practice of exercise in hypertension and to study the correlates of knowledge of exercise in the hypertensive patients. The findings of the study could help in designing intervention and preventive strategies and fill up the existing gap regarding the non-pharmacological treatment of HTN in India.

\section{MATERIALS AND METHODS}

The present study is a quantitative, hospital-based, cross-sectional study conducted in the district of Jamnagar, a coastal region in the western - most part of India for a period of one year, from July 2013 to June 2014. In the study area, Tertiary care centre i.e. Medical College and all the 11 CHCs have NCD clinic. $50 \%$ of the participants were recruited from NCD 
clinic of tertiary care centre and $50 \%$ from the selected CHC's NCD clinic.

\section{Sample size calculation and sampling technique}

Sample size $(\mathrm{N})$ was calculated using the formula $4 \mathrm{pq} / \mathrm{L}^{2}$. Where $\mathrm{p}$ is anticipated population proportional for awareness about Role of exercise in NCDs, $q$ is $100-p$ and $L$ is relative precision. At $95 \%$ confidence interval, taking prevalence (p) as $50 \%{ }^{10}$ and $\mathrm{L}$ as $10 \%$ of $\mathrm{p}$, a sample size of 400 was calculated. Out of the total sample size, half of the study subjects were selected from the tertiary care hospital of the study district and remaining 200 were selected from Community Health Centers (CHCs) of study district by Population proportional sampling method by reviewing the utilization of the NCD clinic patients' data from the previous year. Study district comprises $11 \mathrm{CHCs}$ and 1 tertiary care Hospital. All CHCs have functioning NCD clinic. Thus peripheral public health sector utilization cannot be overlooked so $50 \%$ participants were selected from NCD clinic of selected CHCs and rest of the $50 \%$ from tertiary care hospital. There were $11 \mathrm{CHCs}$ in study district, of which $50 \%$ were chosen through simple random sampling technique. Thus, five $\mathrm{CHCs}$ were taken up and 40 patients from each of $\mathrm{CHCs}$ were taken for the study. Hypertensive patients attending NCD clinics at the Guru Govind singh Government Hospital (GGH) and at the selected Community Health Centres of Jamnagar district formed the study population. Data was collected from patients only on their first visit after the onset of the study. If a patient had been already included in the study, then next patient was taken up for the study to avoid repetition. In the CHCs, 40 patients were selected as consecutive sampling method. If further visit required reaching the sample from selected $\mathrm{CHCs}$, it was done. Where as in NCD clinic of tertiary care centre, sample was divided in 20 working days; everyday 10 patients were selected by consecutive sampling method.

\section{Inclusion criteria}

1. Patients who are aged 30 years or more.

2. Patients who are already diagnosed as having hypertension.

\section{Exclusion criteria}

1. Patients not willing to participate.

2. Patients who are critically or mentally ill.

3. Pregnant patients.

\section{Data collection}

Data collection was done through by personal interview that was carried out using a pre-tested, semi-structured proforma comprising questions about socio-demographic factors, past history, family history, any other co-morbid condition, his/her knowledge and attitude about hypertension and their practices to control the disease including compliance to treatment after reviewing the literature. Pilot study was done on 20 patients then necessary changes were made in proforma. The data of pilot study were not taken in consideration for results. Socio-economic status was estimated on the basis of Modified Prasad's Classification (1961) which was modified according to AICPI (All India Consumer Price Index) of the year 2013 using AICPI. ${ }^{11}$

\section{Statistical analysis}

The data entry was done using Microsoft Office Excel 2007. To summarize the data, descriptive statistics of frequency, percentages, mean and standard deviation (SD) were used. Relationship between various socio-demographic factors and knowledge regarding benefits of exercise was tested with multinomial logistic regression. While analyzing; age group was divided in five categories with class interval of ten. Age above 69 years was taken as reference category. Similarly, male gender, rural locality, literate group, higher socio-economic status (SES) were taken as reference groups. Alpha level was set at to $0.05(5 \%)$ and SPSS version 20 was used for statistical analysis.

\section{Ethical consideration}

The study protocol was reviewed and approved by The Institutional Ethical Committee. An informed consent was taken from all participants of the study after fully explaining the purpose of the study and assuring them of full confidentiality. The interview was conducted in a language they well understood.

\section{RESULTS}

Out of the 400 hypertensive patients enrolled in the study, it was observed that more than half $57 \%$ (228) of the patients were females. The male: female ratio was 1: 1.3. Most i.e. $79 \%$ (316) of the cases were in the age group 40 years to 69 years. Majority i.e. $80.8 \%$ (323), $86.5 \%$ (346) and $61 \%$ (244) of the respondents were Hindus, married and nuclear family respectively. Around one-fourth (26\%) of the patients were illiterate. In the present study, majority of the patients were housewives (45.3\%) while $15.8 \%$ was labourer and $10.5 \%$ was retired. In this study $64.5 \%$ (258) of the patient belonged to the lower socio-economic class. More than three-fourths $(76.1 \%)$ of the patients belonged to urban areas, of which majority belonged to non-slum areas. (Table 1)

The majority $67.5 \%$ (270) were not aware regarding the benefits of exercise in hypertension. Unfortunately, only $8.25 \%$ (33) actually practised any form of exercise. While analyzing the relationship between the knowledge about the benefit and practice of exercise, it was found that patients who were exercising had 9.39 times higher odds of knowledge of its benefit as compared to those who were not. This was statistically significant with binary logistic regression. (Table 2)

The most common form of exercise observed in the study subjects who exercised was walking and $87.9 \%$ (29) practised that. And, the remaining $12.1 \%$ (4) practised other forms of exercise like jogging, cycling etc. However majority i.e. $90.9 \%$ (30) practised for less than the recommended minimum of 30 min per day while only $27.3 \%$ (9) exercised for at least 5 days a week. (Table 3 ) The inferential statistics for Table 4 are as follows. Females were 0.54 times less aware about the benefit of exercise than the males and this was statistically significant by multinomial logistic regression $(p<0.05)$. Also, younger age group had higher odds of knowledge about benefit of exercise; 30-39 years age group had 6.05 times more knowledge about the benefit of exercise followed by $50-59$ years age group had 2.24 times higher knowledge about the benefit of exercise, which was statistically significant $(p<0.05)$. Urban area people had 3.94 times higher awareness about benefit of exercise $(p<0.05)$ whereas urban slum had 0.87 times awareness about benefit of exercise. When education variable was analysed, $80 \%$ lower awareness among illiterate as compared to literates, which was statistically significant $(p<0.05)$. While analyzing the impact of socioeconomic status (SES) odds ratio for lower class was found to be 0.13 , suggests that $13 \%$ less odds of knowledge among lower class, which was highly statistically significant $(p<0.001)$.

\section{DISCUSSION}

In the present study, more than half (57\%) of the hypertensive patients were females which might be attributed to the fact that $40 \%$ of the patients belonged to the geriatric age group of 60 years and above during which period, due being post-menopausal women have higher risk of having HTN. ${ }^{12}$ Jesus ES et al. in their study observed that higher number of patients was females. ${ }^{13}$ In the study by Jardim et al. where a male predominance was found. ${ }^{14}$ In our study, more than half of the patients belonged to 40-59 years, the age group that forms the "work force" of a community. Majority of the participants in the present study were 


\begin{tabular}{|c|c|c|}
\hline Demographic factors & Frequency (n) & Percentage (\%) \\
\hline \multicolumn{3}{|l|}{ Sex } \\
\hline Male & 172 & 43 \\
\hline Female & 228 & 57 \\
\hline \multicolumn{3}{|l|}{ Age (in completed years) } \\
\hline $30-39$ & 30 & 7.5 \\
\hline $40-49$ & 102 & 25.5 \\
\hline $50-59$ & 105 & 26.2 \\
\hline $60-69$ & 109 & 27.3 \\
\hline$>69$ & 54 & 13.5 \\
\hline \multicolumn{3}{|l|}{ Religion } \\
\hline Hindu & 323 & 80.8 \\
\hline Muslim & 75 & 18.7 \\
\hline Others & 2 & 0.5 \\
\hline \multicolumn{3}{|l|}{ Marital Status } \\
\hline Married & 346 & 86.5 \\
\hline Never married & 5 & 1.2 \\
\hline Widow/ widower & 49 & 12.3 \\
\hline \multicolumn{3}{|l|}{ Type of family } \\
\hline Nuclear & 244 & 61 \\
\hline Joint & 86 & 21.5 \\
\hline Three generation & 70 & 17.5 \\
\hline \multicolumn{3}{|l|}{ Education } \\
\hline Illiterate & 104 & 26 \\
\hline Literate & 296 & 74 \\
\hline \multicolumn{3}{|l|}{ Occupation } \\
\hline Labourer & 63 & 15.8 \\
\hline Businessman & 34 & 8.4 \\
\hline Housewife & 181 & 45.3 \\
\hline Retired & 42 & 10.5 \\
\hline Others & 80 & 20 \\
\hline \multicolumn{3}{|l|}{ Socioeconomic class } \\
\hline Higher class (I and II) & 142 & 35.5 \\
\hline Lower class (III, IV and V) & 258 & 64.5 \\
\hline \multicolumn{3}{|l|}{ Locality } \\
\hline Urban non-slum & 215 & 53.8 \\
\hline Urban slum & 89 & 22.3 \\
\hline Rural & 96 & 24 \\
\hline
\end{tabular}

\begin{tabular}{|c|c|c|}
\hline Variables & No. $(n=33)$ & Percentage (\%) \\
\hline \multicolumn{3}{|l|}{ Type of exercise } \\
\hline Walking & 29 & 87.9 \\
\hline Others & 4 & 12.1 \\
\hline \multicolumn{3}{|c|}{ Duration of exercise (in min/ day) } \\
\hline$<30$ & 30 & 90.9 \\
\hline$\geq 30$ & 3 & 9.1 \\
\hline \multicolumn{3}{|c|}{ Frequency of exercise (in days/ week) } \\
\hline$\geq 5$ & 9 & 27.3 \\
\hline 3 to 5 & 22 & 66.7 \\
\hline Sometimes, not fixed & 2 & 6 \\
\hline
\end{tabular}

\begin{tabular}{|c|c|c|c|c|}
\hline \multirow{2}{*}{$\begin{array}{l}\text { Demographic } \\
\text { factor }\end{array}$} & \multicolumn{2}{|c|}{ Aware of Exercise } & \multirow[t]{2}{*}{ OR } & \multirow[t]{2}{*}{$p$ value } \\
\hline & No. & $\%$ & & \\
\hline \multicolumn{5}{|l|}{ Sex } \\
\hline Male & 69 & 53.08 & 1 & \\
\hline Female & 61 & 46.93 & $0.54(0.35-0.83)$ & $0.005^{*}$ \\
\hline \multicolumn{5}{|l|}{ Age (in yrs) } \\
\hline $30-39$ & 19 & 14.62 & $6.045(2.175-16.806)$ & $0.001^{*}$ \\
\hline $40-49$ & 30 & 23.07 & $1.458(0.641-3.317)$ & 0.368 \\
\hline $50-59$ & 41 & 31.54 & $2.242(1.003-5.014)$ & $0.049^{*}$ \\
\hline $60-69$ & 27 & 20.77 & $1.152(0.504-2.634)$ & 0.737 \\
\hline$>69$ & 13 & 10 & 1 & \\
\hline \multicolumn{5}{|l|}{ Locality } \\
\hline Urban & 99 & 76.15 & $3.947(2.159-7.216)$ & $0.001^{*}$ \\
\hline Slum & 15 & 11.54 & $0.867(0.401-1.8770$ & 0.718 \\
\hline Rural & 16 & 12.31 & 1 & \\
\hline \multicolumn{5}{|l|}{ Education } \\
\hline Illiterate & 12 & 9.23 & $0.197(0.103-0.375)$ & $0.001^{*}$ \\
\hline Literate & 118 & 90.77 & 1 & \\
\hline \multicolumn{5}{|l|}{ SES } \\
\hline Higher class & & & & \\
\hline (I and II) & 87 & 66.92 & 1 & \\
\hline $\begin{array}{l}\text { Lower class } \\
\text { (III, IV, V) }\end{array}$ & 43 & 33.08 & $0.126(0.079-0.202)$ & $0.0001 \dagger$ \\
\hline
\end{tabular}

${ }^{*}$ Significant statistical association $(p<0.05)$

$\dagger$ Highly significant statistical association $(p<0.001)$

\begin{tabular}{|c|c|c|c|c|c|}
\hline \multirow{2}{*}{$\begin{array}{l}\text { Practice } \\
\text { exercise }\end{array}$} & \multicolumn{2}{|c|}{ Benefit of Exercise } & \multirow{2}{*}{$\begin{array}{c}\text { Total } \\
(\mathrm{N}=400)\end{array}$} & \multirow[t]{2}{*}{ OR $(95 \% \mathrm{CI})$} & \multirow[t]{2}{*}{$p$ value } \\
\hline & $\begin{array}{c}\text { Aware } \\
(n=130)\end{array}$ & $\begin{array}{l}\text { Unaware } \\
(n=270)\end{array}$ & & & \\
\hline \multirow[t]{2}{*}{ Yes (\%) } & $26(6.5)$ & $7(1.8)$ & $33(8.3)$ & 9.39 & \\
\hline & & & & $\begin{array}{c}\text { (3.9552 to } \\
22.30)\end{array}$ & $0.0001^{*}$ \\
\hline No $(\%)$ & $104(26)$ & $263(65.6)$ & $367(91.7)$ & 1 & \\
\hline
\end{tabular}

married (86.5\%) and were housewives (45.3\%). These findings were in agreement with the study of Jesus ES et al. where majority of the participants were in their fifties, married and housewives. ${ }^{13}$ The literacy rate in the present study was $74 \%$ and $64.5 \%$ of the respondents were from the lower socioeconomic strata.

One of the important finding of this study was that it was observed that almost seven out of ten hypertensive patients were not aware of the benefits of exercise and only eight among hundred hypertensive patients practised any form of exercise. In a study done in Nigeria, $32.7 \%$ knew about the benefits of exercise on HTN control which is similar to the observed proportion of $32.5 \%$ in the present study. However, in the same study they observed that $40 \%$ patients exercised which was much higher 
than the finding of our study..$^{15}$ The practice of exercise was much lower than in a study done in Brazil by Hallal PC et al. ${ }^{16}$ The difference found could be due to the lifestyle of the people and culture. The importance of exercise might not be in knowledge. Many people consider their routine work as the form of exercise in our culture. Lack of the time could be another reason for this. Sensitization of the importance of exercise must be made from the schools for prevention as well as management of the NCDS. This was an important finding as several studies have observed that physical inactivity or lack of exercise was responsible for increased mortality in hypertensive patients. ${ }^{9,17}$ It was found in this study that patients who were exercising had 9.39 times more odds of higher knowledge of its benefit as compared to those who were not. This was found to be statistically significant. Similarly, significant association between knowledge of exercise for BP control and practice was observed in a study done in Nigeria. ${ }^{15}$

The most common form of exercise that was practised by the study subjects who exercised was walking (87.9\%). This was comparable to the finding of Awotidebe TO et al. in 2014 where the most common form of exercise was brisk walking followed by running and cycling. ${ }^{15}$ More than $90 \%$ of who exercised practised the same for less than $30 \mathrm{~min} /$ day while only $27.3 \%$ exercised for at least 5 days a week. In a study done in India by Durai Vanitha et al. $89 \%$ were physically active for more than $30 \mathrm{~min} /$ day. ${ }^{18}$ Another study reported that $11.3 \%$ exercised thrice weekly with $8 \%$ of the respondents practicing exercise for $30 \mathrm{~min} .{ }^{15}$

It was observed that female patients have $46 \%$ less odds of awareness about the benefit of exercise than the male patients and this was found to be statistically significant. It was observed that 30-39 years age group had 6.05 times more odds of knowledge about the benefit of exercise followed by $50-59$ years age group had 2.24 times more odds of higher knowledge about the benefit of exercise, which was statistically significant. Knowledge regarding exercise was statistically associated with age in another study, too. ${ }^{15}$ However, in a study done in rural China, it was observed that older age group ( $\geq 65$ years) and females had higher odds of practising exercise. ${ }^{19-20}$ Urban non-slum area people had 3.94 times more odds of higher awareness about benefit of exercise whereas those belonging to urban slum had $13 \%$ less odds of awareness about benefit of exercise. Patients who were literate exhibited higher awareness and this were statistically significant. Patients belonging to higher SES had higher chances of being aware about positive effects of exercise on HTN and this was highly significant statistically.

\section{CONCLUSION}

Practice and good compliance to self-care behaviours or non-pharmacological treatment in addition to medications is an impactful way to control hypertension and prevent complications in patients of hypertension. Exercise is cornerstone of such self-care behaviours, however knowledge and practice of exercise were found to be poor in the present study. Patients who were females, older than 69 years, lower socio-economic status and have lower knowledge regarding benefits of exercise on hypertension. Since knowledge regarding the benefits of exercise was strongly associated with its practice, health care providers and public health professionals should disburse information about benefits of exercise on HTN in addition to pharmacological and non-pharmacological treatment and while doing so pay more attention to these groups of patients. NCD clinic is also a good opportunity for all the HTN patients to get correct information on lifestyle modifications and continuous follow up.
Limitations: More numbers in term of sample size and multicentre study can form study for generalizability. More variables influencing knowledge, practice and attitude can be studied in details by qualitative methodology.

\section{ACKNOWLEDGEMENT}

To the Department of community medicine Department., Shree M.P. Shah GMC, Jamnagar \& NCD clinic \& cell \& all the participants.

\section{CONFLICT OF INTEREST}

The authors declare that there is no conflict of interest.

\section{ABBREVIATIONS}

NCD clinic: Non Communicable Disease clinic; CHC: Community Health Centre; 3.HTN: Hypertension; 4.CVDs: Cardiovascular diseases 5.SPSS: Statistical Package for Social Science.

\section{SUMMARY}

Conclusion and summary was written under one section of conclusion only so heading of conclusion can be replaced by Conclusion \& Summary.

\section{REFERENCES}

1. Chobanian AV, Bakris GL, Black HR, Cushman WC, Green LA, Izzo Jr JL, etal. The seventh report of the Joint National Committee on Prevention, Detection, Evaluation and Treatment of High Blood Pressure (JNC-7). JAMA. 2003:289(19):2560-72.

2. Kearney PM, Whelton M, Reynolds K, Muntner P, Whelton PK, He J. Global burden of hypertension: analysis of worldwide data. Lancet. 2005;365(9455):217-23.

3. Reddy KS. Hypertension control in developing countries: Genetic issues. J Hum

4. Hypertens. 1996;10:S33-8

5. Anchala R, Kannuri NK, Pant H, Khan H, Franco OH, DiAngelantonio $\mathrm{E}$, et al. Hypertension in India: a systematic review and meta-analysis of prevalence, awareness and control of hypertension. J Hypertens. 2014;32(6):1170-7.

6. Pescatello LS, Franklin BA, Fagard R, Farquhar WB, Kelley GA, Ray CA. Exercise and hypertension. Med Sci Sports Exerc. 2004;36(3):533-53.

7. Gupta R. Trends in hypertension epidemiology in India. J Hum Hypertens. 2004;18(2):73-8.

8. Ibrahim MM, Damasceno A. Hypertension in developing countries. Lancet. 2012;380(9841):611-9

9. Goetzel RZ, Anderson DR, Whitmer RW, Ozminkowski RJ, Dunn RL, Wasserman J. Health Enhancement Research Organization (HERO) Research Committee. The relationship between modifiable health risks and health care expenditures: An analysis of the multi-employer HERO health risk and cost database. J Occup Environ Med. 1998;40(10):843-54.

10. Church TS, Kampert JB, Gibbons LW, Barlow CE, Blair SN. Usefulness of cardio respiratory fitness as a predictor of all-cause and cardiovascular disease mortality in men with systemic hypertension. Am J Cardiol. 2001;88(6):651-6. Pub Med PMID: 11564389.

11. Lwanga SK, Lemeshow S. Sample size determination in health studies: A practical manual.World Health Organization, Geneva. 1991.

12. All India Consumer Price Index (General) for Industrial Workers, [cited 2013 July 22]. Available from http://cyberjournalist.org.in/manisana/aicpinew.html

13. Lima R, Wofford M, Reckelhoff JF. Hypertension in Postmenopausal Women Current Hypertension Reports. 2012;14(3):254-60. Doi: 10.1007/s11906-0120260-0.

14. Jesus ES, Augusto MAO, Gusmão J, MionJúnior D, Ortega K, Pierin AMG Profile of hypertensive patients: biosocial characteristics, knowledge and treatment compliance. Acta Paul Enferm. 2008:21(1):59-65.

15. Jardim PCB, Gondim MRP, Monego ET, Moreira HG, Vitorino PVO, Souza WKSB, et al. Hipertensão arterial e algunsfatores de riscoemuma capital brasileira. Ara Bras Cardiol. 2007:88(4):452-7.

16. Awotidebe TO, Adedoyin RA, Rasaq WA, Adeyeye VO, Mbada CE, Akinola OT et al. Knowledge, attitude and Practice of Exercise for blood pressure control: A cross-sectional survey. Journal of Exercise Science and Physiotherapy. 2014;10(1):1-10

17. Hallal PC, Victora CG, Wells JCK, Lima RC. Physical Inactivity: Prevalence and Associated Variables in Brazilian Adults. Med Sci Sports Exerc. 2003;35(11): 
1894-900

18. Mokdad AH, Marks JS, Stroup DF, Gerberding JL. Actual causes of death in the United States, 2000. JAMA. 2004;291(10):1238-45. Review. Erratum in: JAMA. 2005;293(3):298. JAMA. 2005;293(3):293-4. Pub Med PMID: 15010446.

19. Durai $V$, Muthuthandavan AR. Knowledge and Practice on lifestyle modifications among males with hypertension. Indian Journal of Community Health.
2015;27(1):143-9. ISSN 2248-9509. Available at: http://www.iapsmupuk.org/ journal/index.php//JCH/article/view/541. [Date accessed: 14 sep. 2017].

20. Hu H, Li G, Arao T. Prevalence rates of self-care behaviours and related factors in a rural hypertension population: a questionnaire survey. Int $\mathrm{J}$ Hypertens. 2013;526949. pmid:23819042

Cite this article : Sarkar A, Rathod M, Patel N, Chauhan MM, Makwana NR, Parmar DV. A Cross-Sectional Analytical Study of Knowledge and Practice of Exercise Among Hypertensive Patients attending NCD clinic in Western Gujarat. Int J Med Public Health. 2018;8(4):140-4. 